DOI: https://doi.org/10.24867/08BE32Jovanovic

\title{
IDENTIFIKACIJA ELEMENTARNIH NEPOGODA U SISTEMU ZA UPRAVLJANJE PAMETNIM BROJILIMA
}

\section{IDENTIFICATION OF NATURAL DISASTERS IN SMART METER MANAGEMENT SYSTEM}

\author{
Ivona Jovanović, Fakultet tehničkih nauka, Novi Sad
}

\begin{abstract}
Oblast - ELEKTROTEHNIKA I RAČUNARSTVO
Kratak sadržaj - U ovom radu, predstavljen je servis za upravljanje podacima sa pametnih brojila i opisano je karakteristično ponašanje pametnih brojila tokom elementarnih nepogoda. Analiziran je značaj napredne merne infrastrukture prilikom ispada i na koje sve načine sistemi pametnih brojila olakšavaju upravljanje ispadima. Predstavljen je problem velike količine $i$ učestalosti poruka tokom oluje koja je opterećujuća za sistem. U radu je opisana implementacija rešenja za problem detektovanja elementarnih nepogoda na osnovu događaja.
\end{abstract}

Ključne reči: pametna brojila, elementarna nepogoda, sistem za upravljanje pametnim brojilima, napredna merna infrastruktura.

Abstract - In this paper, we present smart meter managemement service and characteristical behaviour of smart meters during natural disasters. The importance of advanced metering infrastructure during outages is described and in what ways smart meter systems make it easier to manage outages. The problem of large amount and frequency of data during a storm that is burdensome for the system is presented. The paper describes the implementation of a solution to the event-based elemental disaster detection problem.

Keywords: smart meters, natural disaster, SMMS, AMI.

\section{UVOD}

Industrija električne energije suočava se sa izazovima velikih razmera. Decenijama je fokus bio na pouzdanoj proizvodnji električne energije, kao i da cena proizvodnje bude minimalna. Infrastruktura stari i suočava se sa sposobnošću mreže da ostane pouzdana dok ekonomski i globalni faktori utičnu na nestabilnost cene goriva i električne energije.

Uticaj proizvodnje električne energije na životnu sredinu postao je socijalno i političko pitanje i veliki izazov. Svet je fokusiran na razvoj pametne mreže koja će zameniti postojeće mreže električne energije [1]. Prirodne katastrofe i ekstremni vremenski uslovi, naročito uragani rezultuju velikim ekonomskim, socijalnim i fizičkim poremećajima i pričinjavaju velike neprijatnosti stanovnicima u vidu nestanka struje, vode i komunikacija.

\section{NAPOMENA:}

Ovaj rad proistekao je iz master rada čiji mentor je bio dr Darko Čapko, vanr. prof.
Veliki broj studija iz različitih perspektiva, bavi se ovim problemom kako bi pronašli efikasan način za poboljšanje otpornosti kritičnih sistema. Ekstremni vremenski uslovi predstavljaju veoma velik izazov elektrodistribucijama. Zahteva se veoma brzo donošenje odluka, neophodan je pravovremeni odgovor na trenutno stanje [2].

Zadatak ovog rada je da opiše glavne principe i funkcionalnosti napredne merrne infrastrukture (eng. Advanced Metering Infrastructure - AMI) tokom elementarnih katastrofa. Karakteristično ponašanje pametnih brojila za vreme oluje je takvo da je količina generisanih događaja $i$ do 10 puta veća od uobičajene. Takođe pojačana je učestalost generisanja događaja usled čestih ispada. U radu je opisan problem učestalosti i količine podataka koja je opterećujuća za sistem za upravljanje pametnim brojilima. Kao rešenje predstavljen je sistem koji se bavi detekcijom kritičnih stanja i razmatrani su parametri koje je potrebno uzeti u obzir prilikom identifikacije.

Predstavljeni su i predlozi kako je moguće uticati na sistem kako bi se smanjila mogućnost nepotrebne obrade i gubitka podataka. Detaljno su opisani događaji koje šalju pametna brojila i njihov značaj prilikom lociranja i identifikacije ispada. Opisan je sistem za upravljanje pametnim brojilima (eng. Smart Meter Manegement System - SMMS) koja upravlja pametnim brojilima, prihvata događaje generisane od strane pametnih brojila i obrađuje ih. Za potrebe simulacije sistema tokom oluje implementirana je aplikacija koja simulira slanje podataka sa pametnih brojila. Prikazano je testiranje performansi SMMS servisa koristeći implementirani simulator.

U izolaciji je testirano slanje događaja i predstavljani su dobijeni rezultati ovih testova.

\section{TEORIJSKA OSNOVA}

\subsection{Napredna merna infrastruktura}

Napredna merna infrastruktura je integrisan sistem pametnih brojila, komunikacione mreže i sistema za upravljanje podacima koji omogućavaju dvosmernu komunikaciju između distrubicije i korisnika. Sistem omogućava brojne bitne funkcije koje ranije nisu bile moguće ili su se obavljale ručno, kao npr. mogućnost da se daljinski i automatski meri potrošnja električne energije, uključenje/isključenje servisa, detekcija treptanja (tampering), identifikacija i izolacija ispada, nadgledanje napona. Kombinovano sa tehnologijama koje su vezane za korisnika (pametne kuće, programibilna regulacija temperature...), AMI omogućava elektrodistribucijama 
nove programe pomoću kojih je moguća kontrola potrošnje i cena u realnom vremenu [8]. Zaštita od ispada predstavlja još jedan bitan deo sistema zasnovan na prevenciji i predikciji [3]. AMI omogućava dvosmernu komunikaciju, tako da je moguća komunikacija ili izdavanje komandi od strane elektrodistribucije do pametnog brojila ili uređaja za upravljanje potrošnjom. AMI nije ograničen samo na elektrodistribucije, sistem je takav da pokriva gasne kao i vodovodne mreže [4].

\subsection{Pametna brojila}

Predstavljaju napredna brojila koja dobijaju informacije sa korisničkih uređaja i mere potrošnju električne energije. Informacije o potrošnji energije korisnika, prosleđuju se dalje kompaniji radi kontrole i naplate utrošene energije. Sastoje se od senzora i kontrolnih uređaja povezanih komunikacionom infrastrukturom. Podaci koje sadrže uključuju: jedinstveno obeležje samog brojila, vremensku odrednicu, količinu utrošene električne energije kao i mnoge druge. Imaju mogućnost prikupljanja dijagnostičkih podataka o distributivnoj mreži kao i sa kućnih uređaja. Njihova glavna funkcionalnost je merenje potrošnje električne energije i prenos tih vrednosti do sistema za naplatu. Komunikacija je dvosmerna tako da nakon što je potrošnja obračunata potrošač dobija informacije o tome kako da optimizuje potrošnju. Pored toga što dvosmerno komuniciraju sa pametnim uređajima i sistemima za naplatu, pametna brojila mogu da komuniciraju i međusobno [5].

Prednosti su mnogobrojne i različite u zavisnosti od korisnika. Sa aspekta distribucije prednosti predstavljaju unapređeni sistem naplate i očitavanje brojila koji dovodi do ravnomernije proizvodnje, što donosi ogromne uštede, mogućnost upravljanja potrošnjom električne energije, posebno $u$ vreme maksimalne potrošnje, efikasnija potrošnja energije i mrežnih resursa, pojava novih tarifnih modela na tržištu. Sa aspekta vlada, investiranjem u mreže pametnih brojila stimuliše se ekonomija, pomaže očuvanju životne sredine smanjivanjem emitovanja $\mathrm{CO}_{2}$. Podizanjem nivoa svesti korisnika podstiče se smanjivanje potrošnje električne energije.

Omogućavaju bolju prognozu opterećenja u distributivnoj mreži kao i prevenciju većih ispada, bolju efikasnost pouzdanost servisa. S obzirom na to da se komunikacija odvija u oba smera, signali i komande se šalju direktno do pametnih brojila, lokalno korisnicima ili dalje uređajima za distribuciju. Redovno prikupljanje podataka o potrošnji električne energije svih potrošača omogućava elektrodistribucijama da efikasnije upravljaju potražnjom električne energije, kao i da savetuju potrošače kako da efikasnije koriste svoje električne uređaje. Pametna brojila mogu da prate kvalitet električne energije, odnosno faze, napon, jačinu struje, aktivnu i reaktivnu snagu. Pored toga, pametna brojila pomažu u detekciji neautorizovane potrošnje i krađe električne energije [4].

\subsection{Događaji u okviru pametne mreže}

Događaji sa pametnih brojila su osnova mernog sistema. Oni predstavljaju promenu stanja u mreži koja je bitna elektrodistribuciji. Mogu biti ključni pri detektovanju kvarova i neuobičajenih stanja u mreži. Postoje i oni obaveštajnog tipa koji se mogu podeliti na više od 150 vrsta. Mogu predstavljati samo status uređaja u realnom vremenu, ali mogu biti i indikatori kvaliteta isporuke, ukazivati na ispade ili probleme u komunikaciji. Događaji mogu sadržati sledeće informacije: o uređaju sa kog potiče događaj, stanje mreže, tip događaja, nivo alarmantnosti. Tip događaja sadrži informaciju o tome na koji tip procesa se događaj odnosi.

U okviru posmatranog sistema postoji šest tipova događaja koji predstavljaju podskup događaja definisanih u IEC-61968-9 [6]: POWER DOWN: predstavlja nestanak napajanja električnom energijom na delu električne mreže, POWER UP: predstavlja povratak napajanja električnom energijom na delu električne mreže, UNDERVOLTAGE: predstavlja pad vrednosti napona na delu mreže ispod određene granice, UNDERVOLTAGE RETURN TO NORMAL: predstavlja povratak vrednosti napona na delu mreže iznad određene donje granice, OVERVOLTAGE: predstavlja povećanje vrednosti napona na delu mreže iznad određene granice, OVERVOLTAGE RETURN TO NORMAL: predstavlja povratak vrednosti napona na delu mreže ispod određene gornje granice.

\subsection{SMMS}

Sistem za uspravljanje pametnim brojilima (eng. Smart Meter Management System - SMMS) predstavlja poseban servis u okviru DMS sistema. Zadužen je za procesiranje poruka od pametnih brojila i slanje zahteva za očitavanje upućenih ka njima. Podaci koji stižu u SMMS su nove vrednosti na pametnim brojilima. Proces obrade podataka se konfiguriše putem profila pametnih brojila. Profil je moguće dodeliti različitim delovima mreže. Najmanja jedinica kojoj profil može biti dodeljen je fider. Kada je profil dodeljen fideru, događaji sa svih pametnih brojila dodeljenih tom fideru obrađivaće se prema konfiguraciji tog profila. Neki od parametara profila su: koji događaji i merenja su omogućeni, da li su dozvoljena očitavanja, timeout periodi, vreme stabilizacije itd. Promenom pomenutih parametara možemo uticati na to kako će se događaji obrađivati, što je tema ovog rada.

\section{IDENTIFIKACIJA VREMENSKIH NEPOGODA}

Teški vremenski uslovi kao što su uragani, ledene oluje, grmljavina i ostale elementarne katastrofe mogu da izazovu prekide u snabdevanju korisnika električnom energijom. Jaki vetrovi mogu da sruše drveće na nadzemne dalekovode, munja može da ošteti transformatore, prekidače, dalekovode itd. Dok neki ispadi mogu biti kratkotrajni (npr. par sekundi) mnogi ispadi zahtevaju fizičku popravku ili održavanje prenosnog i distributivnog sistema pre nego što se napajanje može obnoviti. Prvi korak prilikom rešavanja ispada sistema jeste detekcija ispada [7]. Ako je zaštitni uređaj telemetrisan, onda je informacija o ispadu primljena preko SCADA sistema. Ova vrsta prekida se naziva neplanirani SCADA ispad. Ako zaštitni uređaj nije telemetrisan, onda informacija o ispadu dolazi od strane korisnika koji pozivima obaveštavaju da su ostali bez napajanja. Otprilike od $70-75 \%$ poziva su oni uzrokovani ispadom servisa, a trećina njih ne zahteva izlazak na teren. Umesto poziva, elektrodistribucije koje imaju AMI su u mogućnosti da prime informaciju o ispadu od događaja koji stižu sa pametnih brojila i poznati su kao „last gasp“ događaji. Ovakvi događaji obezbeđuju bržu 
detekciju ispada od korisničkih poziva, ali ne poseduju ih sve elektrodistribucije.

Vreme koje je potrebno da se brojilo očita iz AMI sistema može uštedeti nekoliko sati ekipama, jer bi u suprotnom morali da idu u polje i ručno provere da li je brojilo ispravno [7]. „Last gasp“ poruke su one koje pametno brojilo pošalje nakon što se ispad dogodio. Prednosti takvih poruka su te da elektrodistribucije ne moraju da čekaju pozive korisnika kako bi identifikovali i locirali ispad. I u slučajevima kada kasne, „last gasp“ poruke dolaze brže od poziva korisnika, naročito u noćnim satima kada korisnici spavaju. Za lociranje ispada ključna je integracija sistema za upravljanje ispadima (eng. Outage Management System - OMS) i AMI sistema. Mnogi OMS proizvodi zahtevaju pozive $15 \%$ korisnika zahvaćenih ispadom, kako bi pronašli tačnu lokaciju kvara i $20 \%$ uspešnih „last gasp“ poruka.

\section{OPIS APLIKATIVNOG REŠENJA}

Zadatak aplikacije je da na osnovu analize učestalosti i količine podataka $\mathrm{u}$ zadatom vremenskom opsegu detektuje neuobičajeno stanje i menja način obrade događaja na SMMS komponenti. Komunikacija između aplikacije i SMMS servisa je dvosmerna. Brža detekcija ispada neposredno znači i bržu restauraciju napajanja. Zbog toga se sve više teži ka automatizovanoj detekeciji i tu primenu nalazi AMI. Servis SMMS prilikom oluje vrši dodelu tzv. storm profila delovima mreže koji su zahvaćeni elementarnim katastrofama. U slučaju elementarnih nepogoda, mnogo veći broj događaja stiže na sistem. Zbog velike količine podataka koja treba da stigne na servis postoji i mogućnost gubitka istih. Iz tog razloga storm profil, za razliku od normalnog, treba definisati na drugačiji način sa drugim vrednostima parametara.

Prvi korak je identifikacija same nepogode. Podrazumevano je praćenje sistema i uobičajenih vrednosti tokom rada sistema u realnom vremenu. Postoji više načina na koje možemo identifikovati olujni režim u sistemu. Jedan od načina je detektovanje velike količine događaja koji stižu na sistem. Analizom broja pristiglih događaja $u$ odnosu na referentno normalno stanje u sistemu dobijamo informaciju o tome da li je došlo do problema.

Drugi način prepoznavanja je analizom samih događaja. Potrebno je vršiti analizu koliko je događajima sa kog pametnog brojila potrebno da stignu na sistem. Ukoliko je vreme pristizanja duže nego referentno uobičajeno vreme možemo zaključiti da je došlo do problema na pomenutom brojilu. Automatizacijom sistema da sam prepozna kada je u stanju opterećenja velikim brojem događaja je ključna, jer tada sistem sam može da reaguje na odgovarajući način. Aplikacija radi na takav način da se od korisnika zahteva unos referentnih vrednosti za prepoznavanje oluje. Svaka mreža je drugačija, ima različiti broj komponenti pa samim tim i pametnih brojila u sistemu. Različiti broj pametnih brojila znači da se različiti broj događaja očekuje u sistemu i da je svaki sistem jedinstven po tom pitanju. Nakon identifikacije sledi rešavanje problema. Predstavljena su tri načina na koje možemo uticati na obradu događaja u SMMS sistemu i sva tri obuhvataju promenu parametara profilne konfiguracije sistema. Profilna konfiguracija se odnosi na deo mreže, u našem slučaju na fider. Svakom fideru pripadaju određena pametna brojila tako da se definisana profilna konfiguracija odnosi i na njih. Promenom parametra vremena stabilizacije (StewTime) utičemo na vreme čekanja na događaj suprotnog ili istog tipa sa istog brojila. Ukoliko za vreme stabilizacije stigne očekivani događaj, dalja obrada se ne nastavlja. Tokom olujnog režima događaji kasne pa je u skladu sa tim potrebno definisati parametar StewTime. Dodeljivanjem većih vrednosti parametru StewTime omogućava se duže čekanje na događaj suprotnog ili istog tipa i time je nepotrebna obrada izbegnuta. Filtriranje tipova i onemogućavanje čitanja sa brojila su sledeći parametri kojima se utiče na smanjenje broja događaja za obradu. Kao što je već napomenuto tokom vremenskih nepogoda pametna brojila generišu veliku količinu podataka veoma frekventno tako da čitanja sa njih nisu neophodna.

Promenom parametara dozvoljena/zabranjena čitanja, profilne konfiguracije onemogućavamo čitanja sa pametnog brojila na kog se ona odnosi. Prilikom filtriranja događaja, bitno je da definišemo prioritetne tipove događaja čija je obrada ključna. Podešavanjem parametra dozvoljeni/zabranjeni događaji, utičemo na kontrolu obrade i tako što se obrađuju samo oni događaji čiji je tip definisan u listi dozvoljenih događaja.

\subsection{Simulacija}

Za potrebe simulacije implemenirana je aplikacija koja simulira realan sistem u kome se šalju događaji sa pametnih brojila na SMMS komponentu. Aplikacija je implementirana u C\# programskom jeziku, koristeći WPF tehnologiju. Kao razvojni framework, korišćen je .NET framework 4.7.1. Simulacija se vrši na dva načina: ručnim slanjem događaja na servis (korisnik sam unosi željene podatke), automatska simulacija događaja sa polja (sistem sam kreira događaje po nasumičnom principu).

\section{REZULTATI I TESTIRANJA}

Testiranje je izvršeno pomoću simulatora za slanje događaja. Simulirano je slanje događaja u dva režima olujnom i normalnom režimu. Normalan režim predstavlja slanje 8-13 događaja po sekundi dok olujni režim odlikuje slanje 80-120 događaja po sekundi.

$\mathrm{U}$ tabeli 1. prikazane su performanse SMMS sistema za testne slučajeve u kojima je olujni režim trajao 20, 30, 60, 90 i 120 minuta i da pri tome implementirano rešenje nije bilo pokrenuto.

$\mathrm{U}$ tabeli 2. prikazane su performanse SMMS sistema za teste slučajeve u kojima je olujni režim trajao 20, 30, 60, 90 i 120 minuta i da je pri tome implementirano rešenje bilo pokrenuto.

Tabela 1. Performanse servisa kada nije pokrenuta aplikacija

\begin{tabular}{|c|l|l|l|l|l|}
\hline $\begin{array}{c}\text { Trajanje } \\
\text { oluje } \\
{[\mathbf{m i n}]}\end{array}$ & $\begin{array}{l}\text { max } \\
\text { CPU } \\
{[\%]}\end{array}$ & $\begin{array}{l}\text { avg } \\
\text { CPU } \\
{[\%]}\end{array}$ & $\begin{array}{l}\text { max } \\
\text { Mem } \\
{[\mathbf{M B}]}\end{array}$ & $\begin{array}{l}\text { min } \\
\text { Mem } \\
{[\mathbf{M B}]}\end{array}$ & $\begin{array}{l}\text { avg } \\
\text { Mem } \\
{[\mathbf{M B}]}\end{array}$ \\
\hline $\mathbf{2 0}$ & 93,2 & 35,39 & 669 & 511 & 624 \\
\hline $\mathbf{3 0}$ & 87,83 & 33,96 & 662 & 599 & 636 \\
\hline $\mathbf{6 0}$ & 82,34 & 36,38 & 684 & 445 & 646 \\
\hline $\mathbf{9 0}$ & 99,9 & 43,49 & 669 & 452 & 609 \\
\hline $\mathbf{1 2 0}$ & 81,38 & 40,03 & 784 & 480 & 697 \\
\hline
\end{tabular}


Tabela 2. Performanse servisa kada je pokrenuta aplikacija

\begin{tabular}{|c|l|l|l|l|l|}
\hline $\begin{array}{c}\text { Trajanje } \\
\text { oluje } \\
\text { [min] }\end{array}$ & $\begin{array}{l}\text { max } \\
\text { CPU } \\
{[\%]}\end{array}$ & $\begin{array}{l}\text { avg } \\
\text { CPU } \\
{[\%]}\end{array}$ & $\begin{array}{l}\text { max } \\
\text { Mem } \\
{[\mathbf{M B}]}\end{array}$ & $\begin{array}{l}\text { min } \\
\text { Mem } \\
{[\mathbf{M B}]}\end{array}$ & $\begin{array}{l}\text { avg } \\
\text { Mem } \\
{[\mathbf{M B}]}\end{array}$ \\
\hline $\mathbf{2 0}$ & 80,01 & 25,51 & 574 & 329 & 528 \\
\hline $\mathbf{3 0}$ & 77,12 & 35,83 & 637 & 343 & 510 \\
\hline $\mathbf{6 0}$ & 76,54 & 31,13 & 589 & 358 & 553 \\
\hline $\mathbf{9 0}$ & 91,44 & 36,39 & 592 & 559 & 575 \\
\hline $\mathbf{1 2 0}$ & 79,66 & 32,74 & 669 & 383 & 596 \\
\hline
\end{tabular}

Iz tabela možemo zaključiti da su performanse procesora poboljšane u svim slučajima u kojima je razvijena aplikacija imala uticaja na servis, što je i očekivano jer je zadatak aplikacije da rastereti procesor. Kod memorijskih performansi, u slučajima u kojima aplikacija nije bila pokrenuta primećujemo veće prosečne vrednosti memorije u odnosu na iste slučajeve u kojima je aplikacija imala uticaj. Najmanji memorijski skok možemo primetiti u slučaju olujnog režima od 90 minuta, kada implementirano rešenje bilo pokrenuto i on iznosi 592-559=33MB dok je najveći skok bio u slučaju oluje od 120 minuta i iznosi 801-493=308MB u kom implementirano rešenje nije bilo pokrenuto, što je i očekivano jer je olujni režim trajao najduže.

Na skok memorije mogu uticati brojni faktori. Prilikom uspostavljanja komunikacije sa servisom dolazi do većih memorijskih skokova, svaki put kada se aplikacija obrati servisu kako bi promenila konfiguraciju dolazi do većih memorijskih skokova. SMMS je kompleksan servis sa velikim brojem funkcionalnosti tako da ne možemo sa sigurnošću da utvrdimo na koji način se memorija ponaša prilikom obrade događaja.

\section{ZAKLJUČAK}

$\mathrm{U}$ ovom radu opisano je rešenje problema identifikacije elementarnih katastrofa od strane SMMS sistema. Identifikacija i pravovremena reakcija na ispade u mreži su ključni jer elementarne katastrofe mogu prouzrokovati značajnu štetu na elektroenergetskoj mreži i mogu dovesti do rasprostranjenih prekida napajanja električnom energijom. Količina događaja koje pametna brojila generišu tokom oluje je opterećujuća za sistem tako da pravovremena obrada i odgovor na elementarnu nepogodu nije moguć. Zadatak SMMS sistema je da obradi događaje koji stižu sa pametnih brojila i prosledi ih zainteresovanim stranama. Ukoliko sistem ne realizuje obradu dovoljno brzo to utiče i na ostale servise, najvažniji od njih je sistem za upravljanje ispadima.

Implementirano rešenje omogućava rasterećenje procesora SMMS servisa tako da je moguća brža obrada događaja i pravovremena reakcija na ispade. Kada je u pitanju memorija, prosečne vrednosti memorije su veće u slučaju kada implementirano rešenje nije pokrenuto što je i bio cilj. Kod skokova memorije nije primećeno veće odstupanje ni u jednom od testiranih slučajeva. Nepotrebna obrada je izbegnuta i događaji su filtrirani tako da je omogućena obrada samo onih validnih i značajnih za detekciju ispada. Dalja unapređenja rešenja su moguća uvođenjem veštačke inteligencije u aplikaciju. Ukoliko bi aplikacija učila na osnovu iskustva, reakcija na događaje bi bila mnogo brža i preciznija. Isključena bi bila analiza mreže i definisanje parametara od strane korisnika.

Posmatranje pristiglih događaja u realnom vremenu omogućava da uvođenje veštačke inteligencije bude sasvim logičan nastavak.

Velika količina podataka $\mathrm{u}$ realnom vremenu daju aplikaciji materijal pomoću koga se može utvrditi kako se događaji ponašaju u normalnom režimu i daju prostora da se identifikuje stanje koje se ne uklapa u već viđene obrazce.

\section{LITERATURA}

[1] Seth Blumsack, Alisha Fernandez, Ready or not, here comes the smart grid!, Energy, vol. 37, no. 1, pp. 61$68,2012$.

[2] Zohreh S. Hosseini, Mohsen Mahoor, Amin Khodaei, AMI-Enabled Distribution Network Line Outage Identification via Multi-Label SVM, IEEE Transactions on Smart Grid, vol. 9 no. 5, 2018.

[3] Yasin Kabalci, A survey on smart metering and smart grid communication, Renewable and Sustainable Energy Reviews, vol. 57, pp. 302-318, 2016.

[4] R. R. Mohassel, A. Fung, F. Mohammadi, K. Raahemifar, A survey on advanced metering infrastructure, International Journal of Electrical Power \& Energy Systems, vol. 63, 2014, pp. 473-484, 2014.

[5] Jixuan Zheng, David Wenzhong Gao, Li Lin, Smart Meters in Smart Grid: An Overview, Green Technologies Conference (IEEE-Green), 2013.

[6] http://webstore.iec.ch/webstore/webstore.nsf/artnum/048719! opendocument (pristupljeno u novembru 2019.)

[7] Hahn Tram, Technical and Operation Considerations in Using Smart Metering for Outage Management, 2008 IEEE/PES Transmission and Distribution Conference and Exposition, 2008.

[8] Chen-Ching Liu, Distribution systems: reliable but not resilient?, IEEE Power and Energy Magazine, vol. 13, no. 3 , pp. $93-96,2015$.

\section{Kratka biografija:}

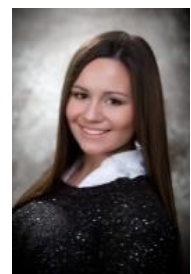

Ivona Jovanović rođena je u Prištini 1995. god. Fakultet tehničkih nauka upisala je 2014. god. Bečelor rad iz oblasti Baze podataka odbranila je 2018. god. Master rad iz oblasti Elekrotehničko i računarsko inženjerstvo odbranila je 2019. god. 